\title{
Pulmonary Edema, CTCAE
}

National Cancer Institute

\section{Source}

National Cancer Institute. Pulmonary Edema, CT CAE. NCI Thesaurus. Code C143789.

A disorder characterized by accumulation of fluid in the lung tissues that causes a disturbance of the gas exchange that may lead to respiratory failure. 